\title{
Cytotoxicity and anticancer drug release behavior of Methionine - coated magnetite nanoparticles as carriers in vitro
}

\section{Faten Eshrati Yeganeh}

Islamic Azad University

\section{Amir Eshrati Yeganeh}

Noor Dahesh Institute of Higher Education

\section{Bahareh Farasati Far}

Iran University of Science and Technology

Iman Akbarzadeh

Sharif University of Technology

Sameer Quazi ( $\nabla$ colonel.quazi@gmail.com )

GenLab Biosolutions Private Limited

\section{Muhammad Safdar}

Gomal University

\section{Research Article}

Keywords: Drug delivery, Letrozole, CoFe2O4 nanoparticles, Methionine, Cytotoxicity, Cell line

Posted Date: January 18th, 2022

DOI: https://doi.org/10.21203/rs.3.rs-1234237/v1

License: (9) (i) This work is licensed under a Creative Commons Attribution 4.0 International License. Read Full License 


\section{Abstract}

An innovative and customized drug delivery system for in vitro cancer treatment has been developed successfully by a simple one-step method. A CoFe $\mathrm{O}_{4} @$ @Methionine core-shell nanoparticle was prepared by the reflux assay, in which amino acid on the surface makes the ferrite biocompatible, enhances the chemical stability of the compound, and increases the drug loading capacity. The synthesized nanoparticles were evaluated using SEM, TEM, FTIR, and VSM, while XRD and TGA analysis verified the presence of a coating amino acid on the surface of CoFe2O4. The appearance of a new peak for $\mathrm{C} \equiv \mathrm{N}$ in the FTIR spectrum validates the synthesis of a letrozole-loaded carrier. Both uncoated CoFe2O4 and methionine-coated $\mathrm{CoFe} 2 \mathrm{O} 4$ nanoparticles behave super-paramagnetically at room temperature, with saturation values of $46 \mathrm{emu} / \mathrm{g}$ and $16.8 \mathrm{emu} / \mathrm{g}$, respectively. SEM and TEM were used to characterize the morphology and size of samples, revealing that the average particle size was around 28-29 nm. The loading of Letrozole and the effect of $\mathrm{pH}(5,7.4)$ on the release behavior of the carrier were studied. The result of the drug release in $\mathrm{pH}(5)$ was about $88 \%$ higher than $\mathrm{pH}$ (7.4). Also, the preparation has been evaluated for determining its cytotoxicity using MCF-7, MDA-MB-231, and MCF10A cell lines as an in vitro model, and the results of in vitro experiments showed that $\mathrm{CoFe}_{2} \mathrm{O}_{4} @$ Methionine could significantly reduce cancer in the cell model. These results demonstrate that core-shell nanoparticles were prepared that are biocompatible and have potential use as drug delivery.

\section{Introduction}

Breast cancer is one of the most often diagnosed cancers around the world, particularly in women, and its cancer patient population is growing each year [1]. Breast malignancies are widely investigated and acknowledged to be hormone-dependent, with estrogen serving as a critical mediator in the progression and spread of breast cancer [2]. Letrozole is one of the most efficient following non-steroidal aromatase inhibitors (Als) for inhibiting the body's excessive estrogen production [3]. Letrozole uses as positive drug to treat breast cancers and highly potent drugs due to its estrogen receptor [4].

To develop new technology for cancer treatment, some significant steps must be taken. One method of execution cancer cells is through targeted drug delivery, in which the term "targeted" refers to the process of eliminating specific malignant cells without harming healthy ones [5]. Recently, spinel ferrites have gained considerable interest for their prospective uses in biomedical fields such as magnetic resonance imaging (MRI), targeted hyperthermia, and controlled drug delivery [6-8]. Among them, Cobalt ferrite $\left(\mathrm{CoFe}_{2} \mathrm{O}_{4}\right)$ has particular significance because of its remarkable magnetization property [9] such as a high coercivity [10], a reasonable saturation magnetization [11], a high Thermal stability [12], a big magnetocrystalline anisotropy [13], a superior mechanical hardness [14], and exceptional chemical stability [15], also appropriate biocompatibility and low toxicity [16]. Furthermore, they can be directly injected into cancer cells and delivered by magnetic field gradient or delivered by other efficient drug delivery systems to release their drugs [17]. 
So far, various magnetic nanoparticles with different formulations have been synthesized for cancer therapy which to improve biomedical applications, surface modification is necessary to coat them with stimuli-responsive [18]. Methionine is a key and major biocompatible amino acid found in the human body, where it performs a variety of physiological roles [19]. Three active functional groups of Methionine $(-\mathrm{COOH},-\mathrm{NH} 2$, and $-\mathrm{SH}$ ) may easily be conjugated to metal atoms (CoFe2O4) and employed as the surface of a carrier to examine previously unknown loading and release behaviors [20]. Wang et al. discovered a simple way to synthesize nanoparticles of Cobalt Ferrite (CoFe2O4) in the presence of Lcysteine (Lys) that could be used as chemotherapeutic agents [21]. It has been shown that FeMn2O4 nanoparticles coated in TEOS and modified with 3-mercaptopropionic acid (MPA) can serve as a suitable delivery vehicle for targeted, site-specific and controlled anti-cancer therapy [22].

In this study, CoFe2O4 nanoparticles coated with methionine using the reflux assay were synthesized and used as a carrier for an anti-cancer drug in one-step. It was determined that the nanoparticles had been characterized using XRD techniques, as well as other methods such as SEM, TEM, VSM, TGA, and FT-IR. Load and release of drug from methionine-coated CoFe2O4 nanoparticles have been described in this study.CoFe204@ Methionine in vitro cytotoxicity was examined by MTT assays with varying concentrations on two cancer cells and normal cells at 24,48 , and $72 \mathrm{~h}$.

\section{Experimental}

\subsection{Materials}

Iron (III) chloride hydrate $\left(\mathrm{FeCl}_{3} \cdot 6 \mathrm{H}_{2} \mathrm{O}\right)$, Cobalt (II) chloride hydrate $\left(\mathrm{CoCl}_{2} \cdot 6 \mathrm{H}_{2} \mathrm{O}\right)$, Sodium hydroxide $(\mathrm{NaOH})$ and Methionine $\left(\mathrm{C}_{5} \mathrm{H}_{11} \mathrm{NO}_{2} \mathrm{~S}\right)$ are used as precursors. Methanol $\left(\mathrm{CH}_{3} \mathrm{OH}\right)$ and deionized water are used as the solvent and Ethanol was used as the rinse solvent. Trypsin-EDTA, purple formazan crystals, Medium RPMI-1640, DMSO, PBS, FBS, MTT, and Penicillin/Streptomycin 100X were purchased from Gibco, USA. Letrozole was purchased from Daroo-Pakhsh Co. MCF-7; MAD-MB-231 and MCF10A cell lines were obtained from Pasteur cell bank, Iran. All the chemicals were purchased from Merck, Germany without further purification.

\subsection{Preparation of methionine Coated $\mathrm{CoFe}_{2} \mathrm{O}_{4}$ Nanoparticles}

Using the coprecipitation process, cobalt ferrite nanoparticles were made. In this experiment, $1.42 \mathrm{~g}$ of $\mathrm{CoCl} 2.6 \mathrm{H} 2 \mathrm{O}$ and $3.24 \mathrm{~g}$ of $\mathrm{FeCl} 36 \mathrm{H} 2 \mathrm{O}$ were dissolved in $180 \mathrm{ml}$ deionized water and agitated for 30 minutes under $\mathrm{N} 2$ pressure before raising the $\mathrm{pH}$ to 12 using $\mathrm{NaOH}(1.5 \mathrm{M})$. The mixture was then supplemented with $1 \mathrm{gram}$ of Methionine dissolved in deionized water. The mixture was heated to between 70 and $80^{\circ} \mathrm{C}$ and refluxed for three hours; the resulting brown precipitate was collected using magnetic separation and washed with deionized water and ethanol. The process is shown in Fig. 1.

\subsection{Characterization}


X-ray diffraction (XRD) analysis of the samples is recorded by the STOE STADI-P, $\theta-2 \theta$ angle scan is obtained at a rate of $1^{\circ} / \mathrm{min}$ over $2 \theta$ range from $10^{\circ}$ to $80^{\circ}$. The amorphous and crystalline phases were estimated by Transmission Electron Microscopy (TEM). Morphology and size of the nanoparticles were estimated using FESEM (model Zeiss-EHT-10.00 kV Germany) and TEM (model Zeiss-EM10C-100 kV Germany). FTIR data was taken in the spectral range from $400-4000 \mathrm{~cm}-1$ by using a model nexus 870 spectroscopy.

The amount of adsorbed and released drug is monitored as functions of soaking time by Ultravioletvisible (UV-Vis) spectra were obtained with a Shimadzu UVS-1700 at $239 \mathrm{~nm}$. The thermal properties (TGA) were performed by a Shimadzu TA Q600 (USA) system from 25 to $800^{\circ} \mathrm{C}$ in the nitrogen atmosphere at a constant heating rate. The magnetic properties of the synthesized Methionine-coated $\mathrm{CoFe}_{2} \mathrm{O}_{4}$ nanoparticles and magnetic nanoparticles $\mathrm{CoFe}_{2} \mathrm{O}_{4}$ were measured at room temperature by a Quantum Design MPMS-XL-7 superconducting quantum interference device (SQUID) with an external magnetic field ranging from $-15 \mathrm{kOe}$ to $+15 \mathrm{kOe}$.

\subsection{Loading Capacity of Letrozole}

$0.0016 \mathrm{~g}$ Letrozole was diluted in $20 \mathrm{ml}$ of methanol, followed by the addition of $0.04 \mathrm{mg}$ MethionineCoFe204 nanoparticles. This mixture was swirled at room temperature for 24 hours to load the drug molecules. After centrifuging the sample dispersion at 6,000 rpm for 12 minutes to collect the Letrozoleloaded nanoparticles, the supernatant was retained for determining the drug loading content. The Letrozole-loaded nanoparticles were collected at room temperature and the supernatants were analyzed using UV-Vis spectroscopy at a wavelength of $239 \mathrm{~nm}$, and the loading capacity was determined using a standard curve with known drug concentrations. The dose of loaded letrozole was determined using Eq (1).

$$
\text { Drugcontent }(\mathrm{mg} / \text { mgsample })=\frac{\mathrm{C}_{0} \mathrm{~V}_{0}-\mathrm{C}_{\mathrm{t}} \mathrm{V}_{\mathrm{t}} \alpha}{\mathrm{w}}(1)
$$

Where $\mathrm{CO}$ represents the initial concentration of Letrozole, Ct represents the drug concentration determined using the Letrozole standard curve, $\mathrm{V} 0$ and $\mathrm{Vt}$ represent the volume of the liquid phase $(\mathrm{ml})$, is the dilution ratio, and $\mathrm{w}(\mathrm{mg})$ is the weight of the nano carrier.

\subsection{In vitro release study and kinetic modeling}

The in-vitro release kinetics of Letrozole were examined by dissolving $15 \mathrm{mg}$ Letrozole-loaded Methionine-CoFe2O4 in $15 \mathrm{ml}$ PBS (phosphate-buffered saline) with varying pH values (5 and 7.4) in the dark and shaking $(100 \mathrm{r} / \mathrm{min})$ at a constant temperature $\left(37^{\circ} \mathrm{C}\right)$. The supernatant $(2 \mathrm{ml})$ is removed and replaced with the same fresh medium PBS with the same $\mathrm{pH}$ value at different time intervals. The percentage of Letrozole released was determined using the UV-Vis method at a wavelength of $239 \mathrm{~nm}$ in accordance with Eq (2). 


$$
\text { Drugrelease }(\%)=\frac{\mathrm{C}_{\mathrm{e}} \times \mathrm{V}}{\mathrm{W}} \times 100(2)
$$

Where $\mathrm{Ce}(\mathrm{mg} / \mathrm{ml})$ represents the concentration of Letrozole in the supernatant, $\mathrm{V}(\mathrm{ml})$ describes the amount of buffer solution, and $\mathrm{w}(\mathrm{mg})$ denotes the amount of drug loaded. The drug release data was mathematically examined using models fitted to kinetic model equations for the purpose of determining the release kinetics and elucidating the release mechanism. Zero-order kinetics (cumulative percent drug released vs. time), first-order kinetics (log percent drug retained vs. time), Higuchi model (cumulative percent drug released vs. square root of time), and Korsmeyer-Peppas equation are all examples of linear form diagrams used in models (log amount of drug released vs. log time). The correlation coefficients ( $r$ ) for the linear curve were determined by regression on the figures above.

\subsection{In vitro cytotoxicity}

MTT assay was performed to determine the cytotoxicity of Methionine-CoFe2O4 nanoparticles on cancer cell lines (MCF-7, MAD-MB-231) and normal cell line (MCF10A). The cells were seeded at a density of 2104 cells per well on a 96 -well plate and cultured at $37^{\circ} \mathrm{C}$ in a humidified incubator with $5 \% \mathrm{CO} 2$ in a mixture containing $1 \%$ penicillin/streptomycin and 10\% fetal bovine serum (FBS). After 24 hours, suspensions of Methionine-CoFe2O4 at various concentrations $(0-80 \mathrm{~g} / \mathrm{ml})$ were added to the medium and incubated continuously for 24 hours, 48 hours, or 72 hours, respectively. After removing the contents of the 96 -well plates, $0.05 \mathrm{ml}$ of MTT solution was added to each well, followed by additional 4 hours of incubation at $37^{\circ} \mathrm{C}$ in a $5 \% \mathrm{CO} 2$ atmosphere. After replacing the medium with $0.05 \mathrm{ml}$ of dimethyl sulfoxide (DMSO), each well was added to dissolve the purple formazan crystals (Ghafelehbashi et al., 2019; iman akbarzadeh et al., 2020). Finally, the absorbance of each well was determined at a wavelength of $570 \mathrm{~nm}$ using a microplate reader (Synergy HT, Bio-Tek Instruments, Winooski, VT). Additionally, the half-maximal inhibitory concentration (IC50) and the rate of cytotoxicity were estimated using Eq (3).

$$
\text { Cellsurvivalrate }=\frac{\text { absorbanceofcontrolcells }}{\text { absorbanceoftreatedcells }} \times 100(3)
$$

\section{Results And Discussion}

\subsection{XRD analysis}

X-ray diffraction was used to characterize the structure of nanoparticles. Figure 2 displays the XRD patterns of CoFe2O4 and Methionine@CoFe2O4 nanoparticles. Methionine@CoFe2O4 nanoparticles (JCPDS No. 98-001-6669), $18.39^{\circ} 30.24^{\circ}, 35.69^{\circ}, 43.33 »$ and $57.23 »$ show that the 2 theta values of the nanoparticles decrease as the methionine enters the network cavities and increases the connection space, indicating that the methionine is incorporated into the network cavities and that the network space is expanded as the methionine is incorporated into the network. The typical diffraction peaks matched to 
the crystal planes (111), (022), (113), (004), (224), (115), and (044). The Debye-Scherrer equation (Eq. 4) indicated that the average size of nanoparticles was $23 \mathrm{~nm}$ :

$$
\mathrm{D}=\frac{\mathrm{K} \lambda}{\beta \cos \theta}(4)
$$

Where $D$ signifies the crystallinity size, $\beta$ is the complete width at half maximum, $K$ is the shape factor, $\theta$ shows the Bragg angle corresponding to the peak and $\lambda$ is $X$-ray wavelength.

\subsection{Morphologic studies of Methionine@CoFe $\mathrm{O}_{4}$ nanoparticles}

FESEM micrographs of the synthesized Methionine@CoFe $\mathrm{O}_{4}$ nanoparticles have been shown in Fig. 3. As observed in Fig. 3 (a) and (b), the spherical shapes with nearly uniform sizes of the Methionine@CoFe $\mathrm{O}_{4}$ nanoparticles are exhibited from the SEM images in which the average size of the spheres is around 28-29 nm. Figure 3(c) and (d) show the TEM micrographs of Methionine@CoFe $\mathrm{O}_{4}$ nanoparticles with slight agglomeration which may be as a result of the nanoparticles' strong magnetic interactions.

\subsection{Magnetic studies}

The magnetic hysteresis loops of the prepared core/shell Methionine@CoFe $\mathrm{O}_{4}$ nanoparticles and bare $\mathrm{CoFe}_{2} \mathrm{O}_{4}$ were measured at room temperature by SQUID in an external magnetic field ranging from -15 $\mathrm{kOe}$ to $+15 \mathrm{kOe}$ as depicted in Fig. 4 . The magnetization curves of bare $\mathrm{CoFe}_{2} \mathrm{O}_{4}$ show that they have a negligible hysteresis loop due to its approximately superparamagnetic behavior. The saturation magnetization value of room temperature for the $\mathrm{CoFe}_{2} \mathrm{O}_{4}$ and Methionine@ $\mathrm{CoFe}_{2} \mathrm{O}_{4}$ nanoparticles are $46 \mathrm{emu} / \mathrm{g}$ and $16.8 \mathrm{emu} / \mathrm{g}$, respectively, which value of $\mathrm{Ms}$ in bare $\mathrm{CoFe}_{2} \mathrm{O}_{4}$ is more than magnetization value after coating with Methionine in the sample. Ms reduction attributed to nonmagnetic Methionine shell around the magnetite nanoparticles.

\subsection{TGA Analysis}

As illustrated in Fig. 5, the presence of Methionine on the CoFe2O4 nanoparticles was further investigated using thermal analysis, which revealed TGA curves for bare CoFe2O4 and Methionine-coated CoFe2O4 nanoparticles. The initial weight loss of bare $\mathrm{CoFe} 2 \mathrm{O} 4$ from room temperature to $150^{\circ} \mathrm{C}$ is probably owing to the elimination of surface hydroxyls or physically adsorbed water, but the curve becomes practically constant at $800^{\circ} \mathrm{C}$ due to the structure's strong stability. This phenomenon was also seen during the fabrication of L-cysteine-coated cobalt ferrite nanoparticles. In the second sample, which Methionine coated cobalt ferrite nanoparticles; the TGA curve shows that the weight loss of $13.83 \%$ is observed at $400^{\circ} \mathrm{C}$ which is related to thermal decomposition of surface-treated $\mathrm{CoFe}_{2} \mathrm{O}_{4}$ with additions of Methionine molecules. So weight loss of Methionine@ $\mathrm{CoFe}_{2} \mathrm{O}_{4}$ has occurred in a range of $400^{\circ} \mathrm{C}$ was related to degradation of Methionine molecules. 


\subsection{FT-IR Analysis}

Figure 6 shows the FTIR spectra of $\mathrm{CoFe}_{2} \mathrm{O}_{4}$, Methionine coated $\mathrm{CoFe}_{2} \mathrm{O}_{4}$ before and after Letrozole loading. In the spectrum of the Methionine amino acid, as a result of the dipole character of their ions, their spectra are a combination of carboxylate salts and the first type amine. The two absorption bands at $1517 \mathrm{~cm}^{-1}$ and $1630 \mathrm{~cm}^{-1}$ are ascribed to the symmetric and asymmetric $\mathrm{N} \otimes \mathrm{H}$ bending, respectively. Also symmetric and asymmetrical stretching $\mathrm{COO}$ band assigned at $1419 \mathrm{~cm}-1$ and $1600 \mathrm{~cm}-1$. Peaks of the $1232 \mathrm{~cm}-1-1330 \mathrm{~cm}-1$ region refer to the $\mathrm{C} \otimes 0$ band. The absorption bands between 400 and 600 $\mathrm{cm}-1$ in the spectra of CoFe2O4 correspond to the intrinsic vibrations of tetrahedral and octahedral metaloxygen complexes, respectively, which are primarily determined by the Fe-O distances. The peaks of Methionine which is determined by the spot chain in the Spectrum were similar with peaks of Methionine@CoFe $\mathrm{O}_{4}$ which clearly shows the presence of the Methionine on the surface of $\mathrm{CoFe}_{2} \mathrm{O}_{4}$. The absorption bands in Letrozole spectrum around 671 and $1007 \mathrm{~cm}^{-1}$ are caused by bending of $\equiv \mathrm{C}-\mathrm{H}$ and spectra around 1143 and $1262 \mathrm{~cm}^{-1}$ related to $C \otimes 0$. The peak in region $1447-1500 \mathrm{~cm}^{-1}$ attributed to aromatic ring and peaks in the $1417 \mathrm{~cm}^{-1}, 1640-1670 \mathrm{~cm}^{-1}$ and $2240 \mathrm{~cm}^{-1}$ region refer to the $\mathrm{C}=\mathrm{C}$, $\mathrm{C}=\mathrm{N}$ and $\mathrm{C} \equiv \mathrm{N}$ stretching respectively. Also peaks at $3114 \mathrm{~cm}^{-1}$ attributed to $\mathrm{CH} \mathrm{sp}^{2}$ hybridized stretching. However, the capacity of the loading drug can be attributed to the shell, which could hold Letrozole molecules. The $\mathrm{C} \equiv \mathrm{N}$ band at $2240 \mathrm{~cm}^{-1}$ present in Methionine@CoFe $\mathrm{O}_{4}$ appears after Letrozole loading, it suggests that the hydrogen bond has formed between the carboxylic group of Methionine and Letrozole molecules, also aromatic ring bands are shifted from $1447 \mathrm{~cm}^{-1}$ to lower $1361 \mathrm{~cm}^{-1}$ when bonding are formed between sure face of carrier and the Letrozole. On the other hand, the entire band which relates to Methionine present in the Methionine@ $\mathrm{CoFe}_{2} \mathrm{O}_{4}$ almost diminishing after Letrozole loading which can be verified by the FTIR.

\subsection{In vitro Loading capacity and release of Letrozole}

To calculate the Letrozole loading capacity of the sample at $239 \mathrm{~nm}$ wavelength was used UV-Vis spectroscopy. To determine the loading capacity of Letrozole on the Methionine@CoFe $\mathrm{O}_{4}$ with different initial Letrozole concentrations, the amount of Methionine@CoFe2O4 was transferred to $20 \mathrm{ml}$ of different initial Letrozole concentrations. When the initial drug concentration is $0.08 \mathrm{mg} / \mathrm{ml}$, the highest loading capacity of the Methionine@CoFe2O4 nanoparticle is $0.025 \mathrm{mg} / \mathrm{mg}$, indicating that $0.62 \mathrm{mg}$ of drug is loaded into $1 \mathrm{mg}$ of nanoparticle. The loading capacity determined in this work is highly dependent on the initial drug concentrations, as illustrated in Fig. 7.

Following that, Letrozole-loaded Methionine@CoFe2O4 nanoparticles are suspended in a PBS buffer media with various $\mathrm{pH}$ values corresponding to the simulated environment of tumors, namely $\mathrm{pH}(5)$ and $\mathrm{pH}(7.4)$, which corresponds to the physiological $\mathrm{pH}$ of the body at $37^{\circ} \mathrm{C}$, for 72 hours. At both pHs, Fig. 8 depicts the cumulative drug release of Letrozole from Methionine@CoFe204. As can be seen, drug release under acid solution circumstances $\mathrm{pH}(5)$ is significantly more than under neutral solution conditions $\mathrm{pH}$. (7.4). Additionally, this study discovered that the release of Letrozole from the carrier 
happens rapidly in the first 8 hours and then gradually slows down to 72 hours. The cause for the quick dissolution of Letrozole on the surface of Methionine @CoFe2O4 nanoparticles is unknown. Following that, the delayed release of Letrozole appears to be caused by physical and chemical interactions between Letrozole and Methionine@CoFe2O4. As stated in the literature, the model delivery system is pH sensitive, which is critical for drug delivery because at neutral $\mathrm{pH}(7.4)$, the modest release rate of the medication alleviates anti-cancer drug side effects on normal cells and drug loss through blood transportation. While acidic conditions $\mathrm{pH}$ (5) are associated with intracellular lysosomes, endosomes, or malignant tissues, which may facilitate the active release of anticancer drugs [26]. The release behavior of letrozole-loaded Methionine@CoFe2O4 nanoparticles was determined in this study using mathematical models. Each model with a higher linear regression coefficient (closer to 1) represents the optimum sample release's kinetic model. Table 1 shows the coefficient of determination $\left(R^{2}\right)$ for each model at various $\mathrm{pH}$ values ( 5 and 7.4). As can be seen, the $\mathrm{pH}$ values released correspond to the Korsmeyer-Peppas model. The obtained $n$ values $(n=0.45)$ in the Korsmeyer-Peppas model for these two settings show that letrozole molecules are released from Methionine@CoFe2O4 nanoparticles via the Fickian diffusion mechanism.

Table 1

The release kinetic models and the parameters obtained for Methionine@CoFe $\mathrm{O}_{4}$ nanoparticles.

\begin{tabular}{|c|c|c|c|}
\hline \multirow[t]{2}{*}{ Release Model } & \multirow[t]{2}{*}{ Equation } & \multicolumn{2}{|l|}{$\mathbf{R}^{2}$} \\
\hline & & pH 5 & $\mathrm{pH} 7.4$ \\
\hline Zero-Order & $\mathrm{C}_{\mathrm{t}}=\mathrm{C}_{0}+\mathrm{K}_{0} \mathrm{t}$ & $\mathrm{R}^{2}=0.8984$ & $\mathrm{R}^{2}=0.7340$ \\
\hline Korsmeyer-Peppas & $M_{t} / M=K_{t}^{n}$ & $\mathrm{R}^{2}=0.9904$ & $\mathrm{R}^{2}=0.8875$ \\
\hline & & $n=0.4365$ & $n=0.3969$ \\
\hline First-Order & $\log C=\log C 0+K_{t} / 2.303$ & $\mathrm{R}^{2}=0.9528$ & $\mathrm{R}^{2}=0.7574$ \\
\hline Higuchi & $\mathrm{Q}=\mathrm{K}_{\mathrm{H}} \sqrt{ } t$ & $R^{2}=0.9764$ & $\mathrm{R}^{2}=0.8746$ \\
\hline
\end{tabular}

As is well known, the cytotoxicity of magnetic nanoparticles is dependent on several parameters, including degree of aggregation, surface area, hydrophobicity, surface coating, and particle size [23]. As demonstrated in cytotoxicity experiments using the MTT test on human breast cancer cells (MCF-7, MDAMB-231) and normal cells (MCF10A). For 24, 48, and 72 hours, cells were treated with free letrozole, Methionine@CoFe2O4 nanoparticles, and letrozole loaded on Methionine@CoFe2O4 nanoparticles at various doses $(0-40 \mathrm{~g} / \mathrm{ml})$. The results indicated that Methionine@CoFe2O4 is almost as toxic to cancer cells as free letrozole, indicating that the letrozole-Methionine@CoFe2O4 nanoparticles are more readily internalized via the receptor-mediated endocytosis mechanism, whereas free letrozole is transported into cells via a passive diffusion mechanism [24]. Additionally, it was revealed that letrozole-methionine 
@CoFe204 was more cytotoxic to MCF-7 cells than to MDA-MB-231 cells. Additionally, normal MCF10A cells were treated with Methionine @CoFe2O4 and letrozole-Methionine@CoFe2O4 at the same doses. The results demonstrated that Methionine@CoFe2O4 and letrozole-Methionine@CoFe2O4 exhibited no detectable toxicity on MCF10A cells after 72 hours of treatment, indicating that they are biocompatible enough to be used as a drug delivery system. This finding indicated that loading the drug on a carrier boosted the growth inhibitory effect on cancer cells synergistically, indicating the therapeutic potential of Methionine@CoFe2O4. The viability of MCF-7 cells is shown in Fig. 9, while that of MDA-MB-231 cells is presented in Fig. 10. Table 2 summarizes the IC50 values for the free drug and Letrozole loaded on Methionine@CoFe2O4 formulations against MCF7 and MDA-MB-231 cells.

Table 2

IC50 values of Letrozole and Letrozole-Methionine@CoFe $\mathrm{O}_{4}$ after 24, $48 \mathrm{~h}$ and $72 \mathrm{~h}$ in MCF-7 and MDA-MB-231 cells.

\begin{tabular}{|llll|}
\hline Cell lines & Incubation time & \multicolumn{2}{l|}{ IC50 $\left(\boldsymbol{\mu g} / \mathrm{ml}^{-1}\right.$ Letrozole $)$} \\
\cline { 3 - 4 } & & Free Letrozole & Letrozole loaded on Methionine@CoFe $\mathrm{O}_{4}$ \\
\hline MCF-7 & $24 \mathrm{~h}$ & $63.52 \pm 1.91$ & $48.43 \pm 1.75$ \\
& $48 \mathrm{~h}$ & $42.36 \pm 1.33$ & $26.63 \pm 1.44$ \\
& $72 \mathrm{~h}$ & $33.90 \pm 1.34$ & $15.10 \pm 0.81$ \\
\hline MDA-MB-231 & $24 \mathrm{~h}$ & $81.10 \pm 1.52$ & $69.04 \pm 0.93$ \\
& $48 \mathrm{~h}$ & $61.08 \pm 0.92$ & $38.32 \pm 1.50$ \\
& $72 \mathrm{~h}$ & $44.14 \pm 0.80$ & $17.47 \pm 0.59$ \\
\hline
\end{tabular}

\section{Conclusions}

Methionine@CoFe2O4 nanoparticles were produced in this study and the drug delivery and in vitro cytotoxicity were studied. Magnetic nanoparticles with a methionine coating demonstrated increased colloid stability and biocompatibility. The potential of Methionine@CoFe2O4 nanoparticles to transport drugs in vitro is demonstrated using letrozole as a model drug at body temperature $\left(37^{\circ} \mathrm{C}\right)$, which exhibited $\mathrm{pH}$-dependent release behavior. It was discovered that the efficacy and selectivity of the drug carrier system can benefit the suppression of rapid drug release in neutral blood systems but accelerate drug release in acidic tumor cells. MTT experiments revealed that Methionine@CoFe2O4 as a model carrier had a low cytotoxicity even at high concentrations after 72 hours of treatment, but LetrozoleMethionine@CoFe2O4 exhibited a high cytotoxicity in both types of cancer cells. As a result, the Methionine@CoFe2O4 Nanocarrier is projected to be a viable drug delivery system that might be used in therapy.

\section{Declarations}


- Availability of Data and Materials: N/A

- Conflict of Interest: Authors declare no competing interest, intellectual or financial.

- Funding: No funding was provided for the research or publication of the article.

- Authors Contribution: All authors have contributed equally in experimentation, planning as well as manuscript writing.

- Acknowledgements: N/A

\section{References}

1. H.J. Burstein, G. Curigliano, S. Loibl, P. Dubsky, M. Gnant, P. Poortmans, M. Colleoni, C. Denkert, M. Piccart-Gebhart, M. Regan, H.J. Senn, E.P. Winer, B. Thurlimann, Estimating the benefits of therapy for early-stage breast cancer: The St. Gallen International Consensus Guidelines for the primary therapy of early breast cancer 2019, Ann. Oncol. 30 (2019) 1541-1557. https://doi.org/10.1093/annonc/mdz235.

2. Y. Feng, M. Spezia, S. Huang, C. Yuan, Z. Zeng, L. Zhang, X. Ji, W. Liu, B. Huang, W. Luo, B. Liu, Y. Lei, S. Du, A. Vuppalapati, H.H. Luu, R.C. Haydon, T.C. He, G. Ren, Breast cancer development and progression: Risk factors, cancer stem cells, signaling pathways, genomics, and molecular pathogenesis, Genes Dis. 5 (2018) 77. https://doi.org/10.1016/J.GENDIS.2018.05.001.

3. A.M. Yang, N. Cui, Y.F. Sun, G.M. Hao, Letrozole for Female Infertility, Front. Endocrinol. (Lausanne). 12 (2021) 737. https://doi.org/10.3389/fendo.2021.676133.

4. M. Sönmezer, V. Turan, The ART patient with a history of estrogen-receptor positive cancer, Assist. Reprod. Tech. (2021) 309-314. https://doi.org/10.1002/9781119622215.CH51.

5. A.L.C. d. S.L. Oliveira, T. Schomann, L.F. de Geus-Oei, E. Kapiteijn, L.J. Cruz, R.F. de Araújo Junior, Nanocarriers as a Tool for the Treatment of Colorectal Cancer, Pharm. 2021, Vol. 13, Page 1321. 13 (2021) 1321. https://doi.org/10.3390/PHARMACEUTICS13081321.

6. H. Jalili, B. Aslibeiki, N. Eskandarzadeh, Advanced applications of spinel ferrite nanoparticles in medicine: Magnetic hyperthermia, magnetic resonance imaging and targeted drug delivery, Iran. J. Phys. Res. 21 (2021) 219-242. https://doi.org/10.47176/IJPR.21.2.21207.

7. K.K. Kefeni, T.A.M. Msagati, T.T. Nkambule, B.B. Mamba, Spinel ferrite nanoparticles and nanocomposites for biomedical applications and their toxicity, Mater. Sci. Eng. C. 107 (2020). https://doi.org/10.1016/J.MSEC.2019.110314.

8. A. SOUFI, H. HAJJAOUI, R. ELMOUBARKI, M. ABDENNOURI, S. QOURZAL, N. BARKA, Spinel ferrites nanoparticles: Synthesis methods and application in heterogeneous Fenton oxidation of organic pollutants - A review, Appl. Surf. Sci. Adv. 6 (2021) 100145.

https://doi.org/10.1016/J.APSADV.2021.100145.

9. V.P. Senthil, J. Gajendiran, S.G. Raj, T. Shanmugavel, G. Ramesh Kumar, C. Parthasaradhi Reddy, Study of structural and magnetic properties of cobalt ferrite (CoFe204) nanostructures, Chem. Phys. Lett. 695 (2018) 19-23. https://doi.org/10.1016/J.CPLETT.2018.01.057. 
10. C. Zhao, A. Gao, Y. Yang, C. Tu, A. Bhutani, K.A. Walsh, S. Gong, D.P. Shoemaker, High-quality CoFe2O4 thin films with large coercivity grown via a wet chemical route, AIP Adv. 9 (2019) 035126. https://doi.org/10.1063/1.5085232.

11. F.L.A. Machado, J.M. Soares, O.L.A. Conceição, E.S. Choi, L. Balicas, Magnetic properties of the nanocomposite CoFe2O4/FeCo-FeO at a high H/T regime, J. Magn. Magn. Mater. 424 (2017) 323326. https://doi.org/10.1016/J.JMMM.2016.10.079.

12. M. Bastianello, S. Gross, M.T. Elm, Thermal stability, electrochemical and structural characterization of hydrothermally synthesised cobalt ferrite (CoFe204), RSC Adv. 9 (2019) 33282-33289. https://doi.org/10.1039/C9RA06310B.

13. H. Jalili, B. Aslibeiki, A.G. Varzaneh, V.A. Chernenko, The effect of magneto-crystalline anisotropy on the properties of hard and soft magnetic ferrite nanoparticles, Beilstein J. Nanotechnol. 10133. 10 (2019) 1348-1359. https://doi.org/10.3762/BJNAN0.10.133.

14. J. Venturini, T.B. Wermuth, M.C. Machado, S. Arcaro, A.K. Alves, A. da Cas Viegas, C.P. Bergmann, The influence of solvent composition in the sol-gel synthesis of cobalt ferrite (CoFe2O4): A route to tuning its magnetic and mechanical properties, J. Eur. Ceram. Soc. 39 (2019) 3442-3449. https://doi.org/10.1016/J.JEURCERAMSOC.2019.01.030.

15. E.M. Elsayed, H.F. Khalil, I.A. Ibrahim, M.R. Hussein, M.M.B. El-Sabbah, The Significance of Buffer Solutions on Corrosion Processes of Cobalt Ferrite CoFe 204 Thin Film on Different Substrates, Comb. Chem. High Throughput Screen. 23 (2020) 599-610. https://doi.org/10.2174/1386207323666191217130209.

16. M. Lickmichand, C.S. Shaji, N. Valarmathi, A.S. Benjamin, R.K. Arun Kumar, S. Nayak, R. Saraswathy, S. Sumathi, N. Arunai Nambi Raj, In vitro biocompatibility and hyperthermia studies on synthesized cobalt ferrite nanoparticles encapsulated with polyethylene glycol for biomedical applications, Mater. Today Proc. 15 (2019) 252-261. https://doi.org/10.1016/J.MATPR.2019.05.002.

17. M. Wu, S. Huang, Magnetic nanoparticles in cancer diagnosis, drug delivery and treatment (Review), Mol. Clin. Oncol. (2017) 738-746. https://doi.org/10.3892/mco.2017.1399.

18. R. Baghban, M. Afarid, J. Soleymani, M. Rahimi, Were magnetic materials useful in cancer therapy?, Biomed. Pharmacother. 144 (2021) 112321. https://doi.org/10.1016/J.BIOPHA.2021.112321.

19. M.J. Lopez, S.S. Mohiuddin, Biochemistry, Essential Amino Acids, StatPearls Publishing, 2020. https://www.ncbi.nlm.nih.gov/books/NBK557845/ (accessed November 30, 2021).

20. F. Sang, X. Zhang, F. Shen, Fluorescent methionine-capped gold nanoclusters for ultra-sensitive determination of copper(II) and cobalt(II), and their use in a test strip, Microchim. Acta 20191866. 186 (2019) 1-9. https://doi.org/10.1007/S00604-019-3428-3.

21. G. Wang, F. Zhou, X. Li, J. Li, Y. Ma, J. Mu, Z. Zhang, H. Che, X. Zhang, Controlled synthesis of Lcysteine coated cobalt ferrite nanoparticles for drug delivery, Ceram. Int. 44 (2018) 13588-13594. https://doi.org/10.1016/J.CERAMINT.2018.04.193.

22. M. Amoli-Diva, M. Daghighi Asli, S. Karimi, FeMn2O4 nanoparticles coated dual responsive temperature and $\mathrm{pH}$-responsive polymer as a magnetic nano-carrier for controlled delivery of 
letrozole anti-cancer, Nanomedicine J. 4 (2017) 218-223.

https://doi.org/10.22038/NMJ.2017.04.003.

23. P. Kush, P. Kumar, R. Singh, A. Kaushik, Aspects of high-performance and bio-acceptable magnetic nanoparticles for biomedical application, Asian J. Pharm. Sci. (2021).

https://doi.org/10.1016/J.AJPS.2021.05.005.

24. Y. He, R.F. de Araújo Júnior, L.J. Cruz, C. Eich, Functionalized Nanoparticles Targeting TumorAssociated Macrophages as Cancer Therapy, Pharmaceutics. 13 (2021) 1670. https://doi.org/10.3390/pharmaceutics13101670.

\section{Figures}

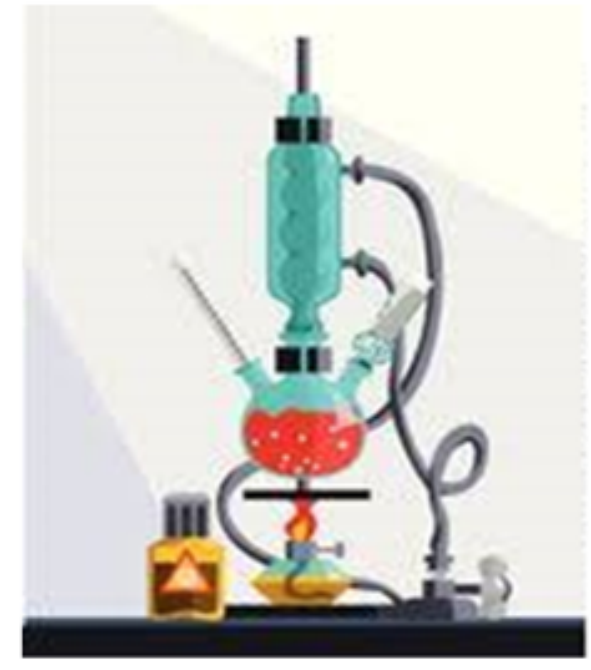

$\mathrm{CoCl}_{2} .6 \mathrm{H}_{2} \mathrm{O}$

$\mathrm{FeCl}_{3} \cdot 6 \mathrm{H}_{2} \mathrm{O}$

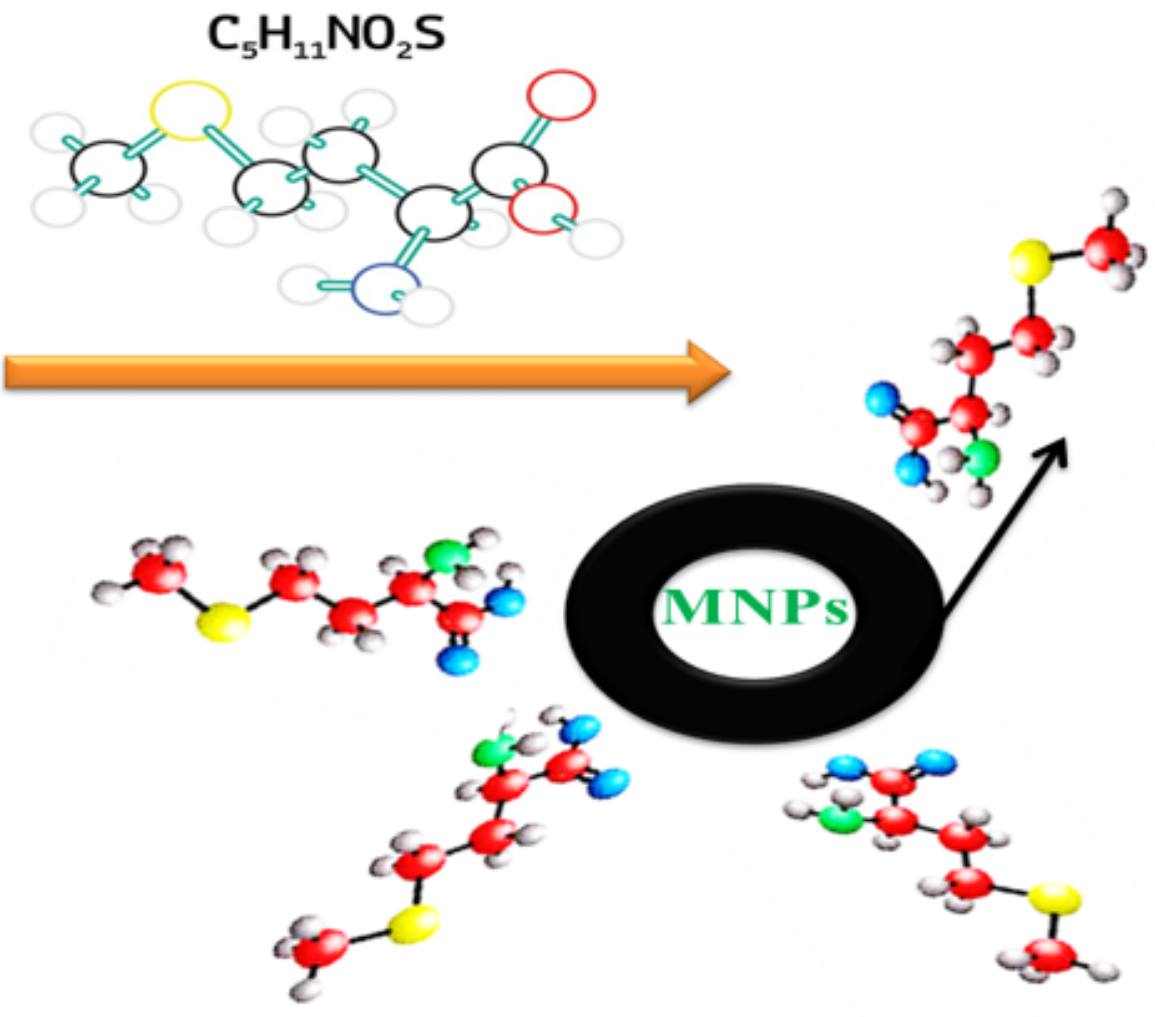

\section{Figure 1}

Schematic shows the synthesis and structures of Methionine@CoFe $\mathrm{O}_{4}$ nanoparticles. 


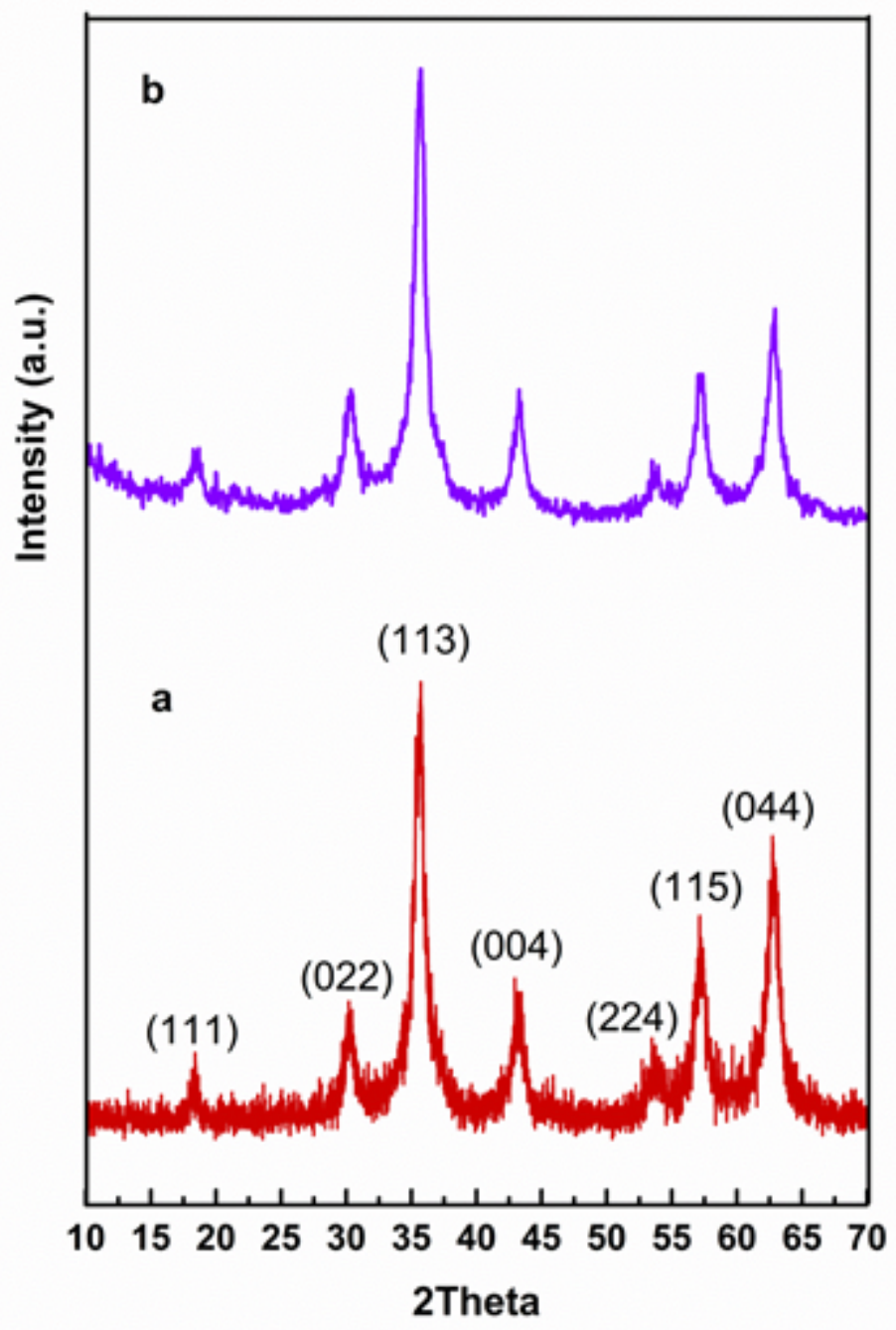

Figure 2

The XRD patterns of $\mathrm{CoFe}_{2} \mathrm{O}_{4}$ nanoparticles (a) and Methionine@CoFe $\mathrm{O}_{4}$ nanoparticles (b). 


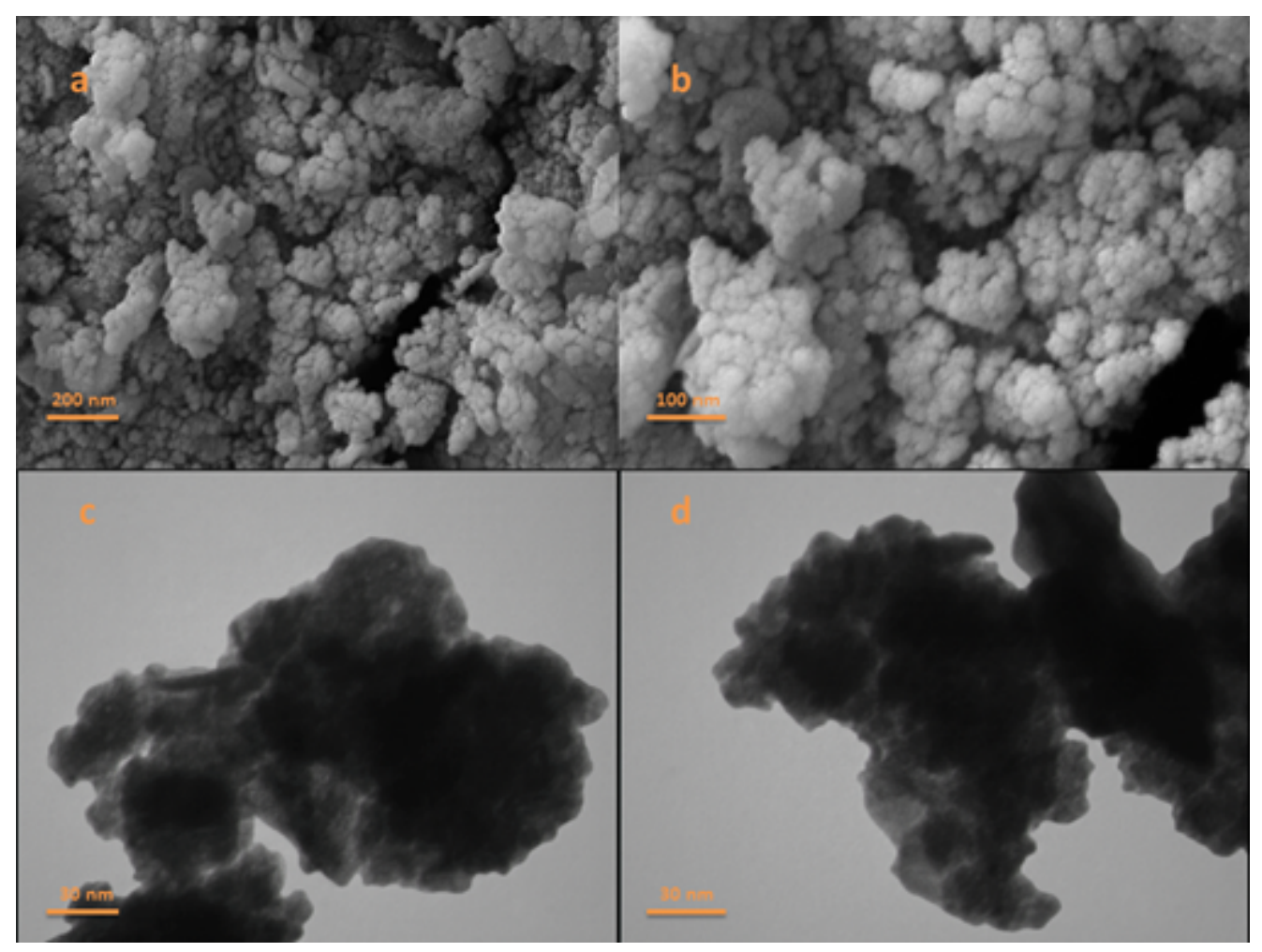

Figure 3

SEM images of Methionine@CoFe $\mathrm{O}_{4}$ nanoparticle (a-b) and TEM images of Methionine@CoFe $\mathrm{O}_{4}$ nanoparticles (c-d). 


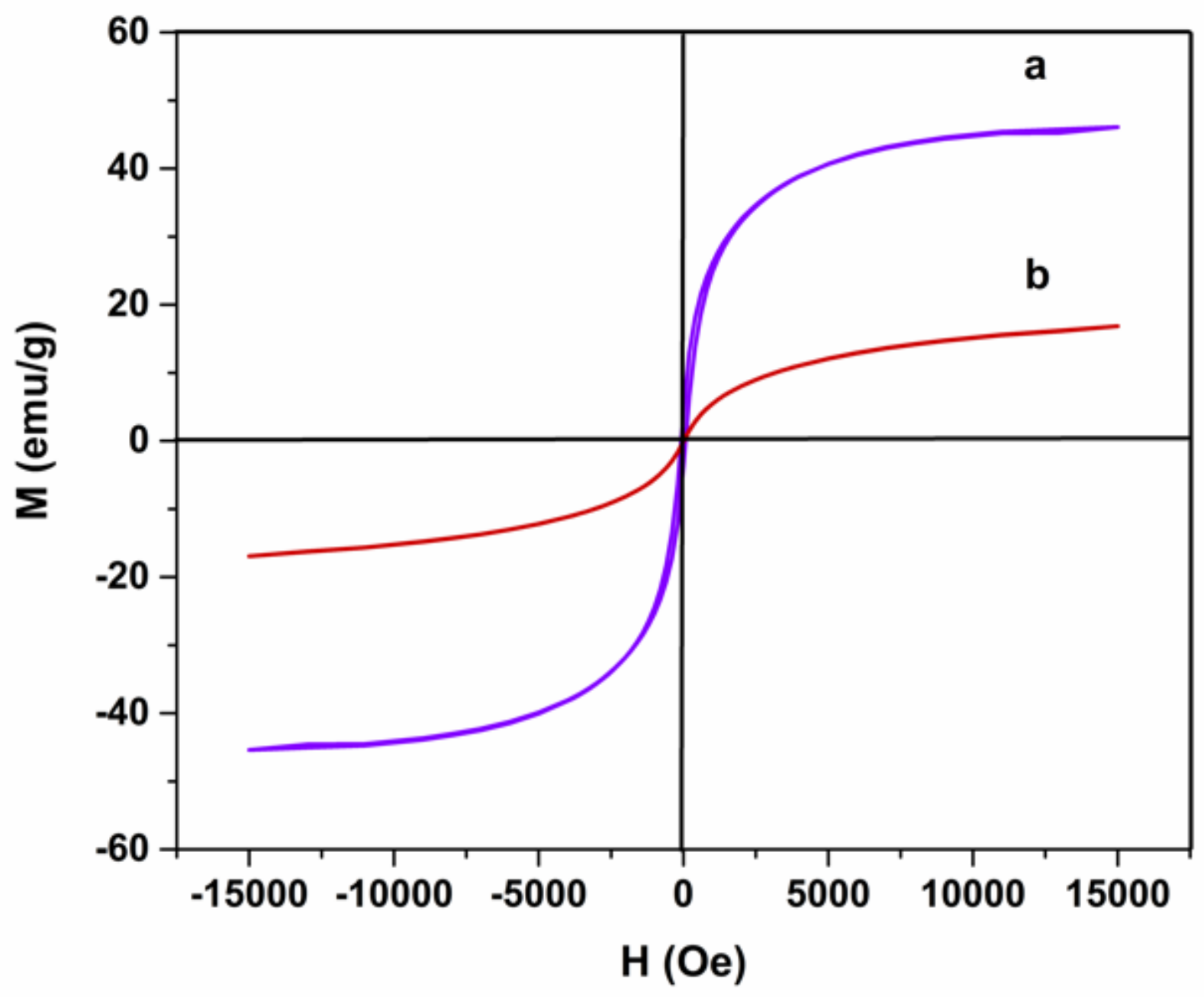

Figure 4

$\mathrm{M}-\mathrm{H}$ curves of $\mathrm{CoFe}_{2} \mathrm{O}_{4}$ nanoparticles (a) and Methionine@CoFe $\mathrm{O}_{4}$ nanoparticles (b). 


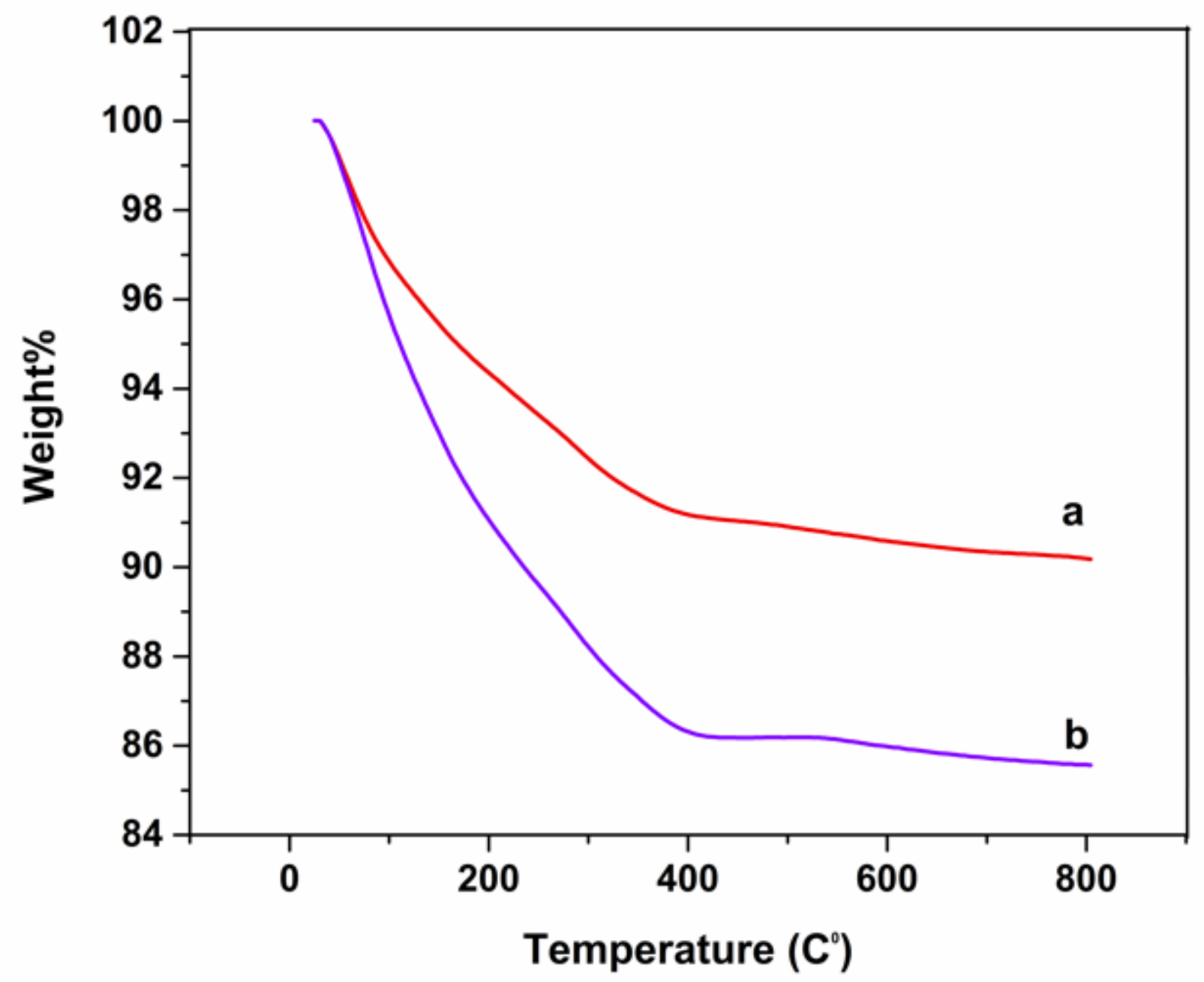

Figure 5

TGA curves of bare $\mathrm{CoFe}_{2} \mathrm{O}_{4}(\mathrm{a})$, Methionine@ $\mathrm{CoFe}_{2} \mathrm{O}_{4}$ nanoparticles (b). 


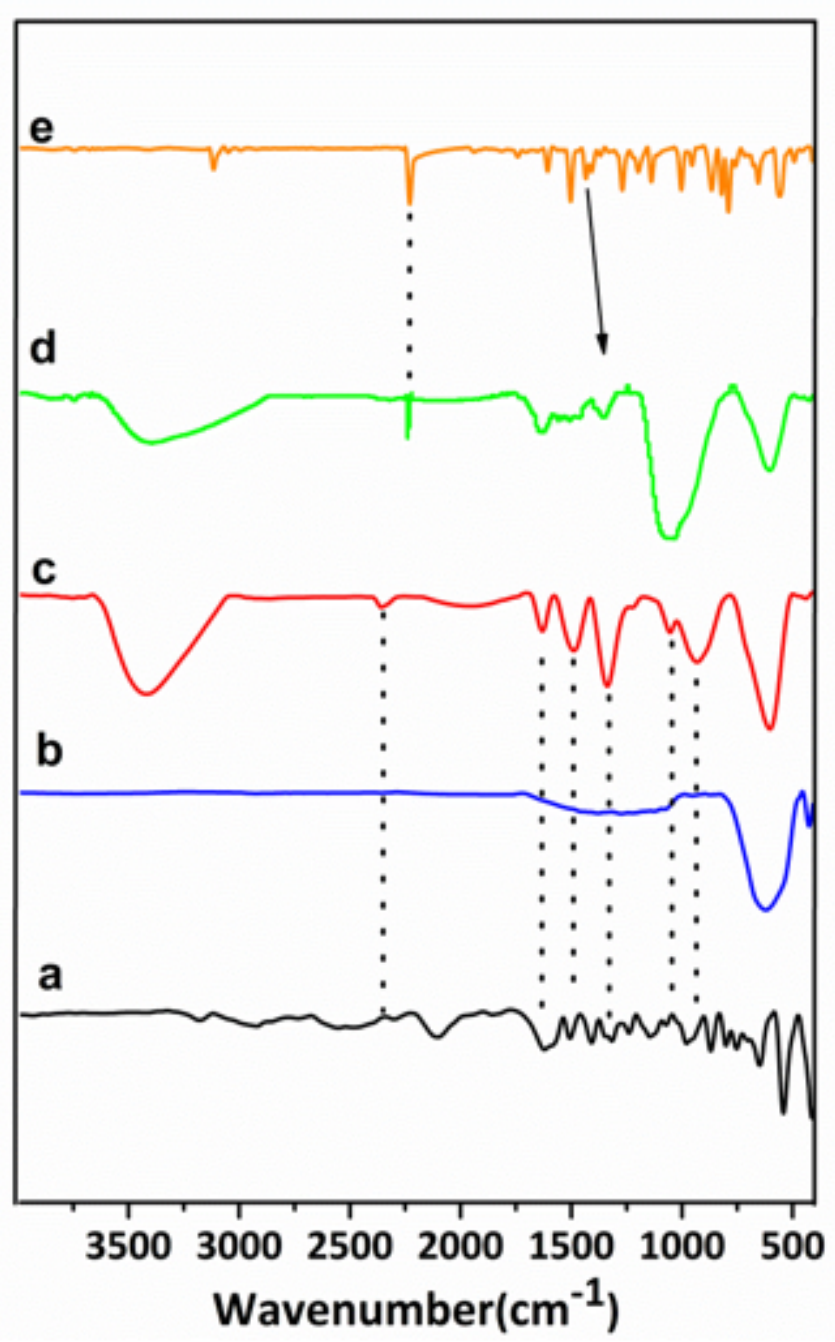

Figure 6

The FTIR spectra of before and after Letrozole loading on carrier (a) Methionine, (b) $\mathrm{CoFe}_{2} \mathrm{O}_{4}$, (c) Methionine@CoFe $\mathrm{O}_{4}$, (d) Letrozole loaded on the Methionine@ $\mathrm{CoFe}_{2} \mathrm{O}_{4}(\mathrm{e})$ Letrozole. 


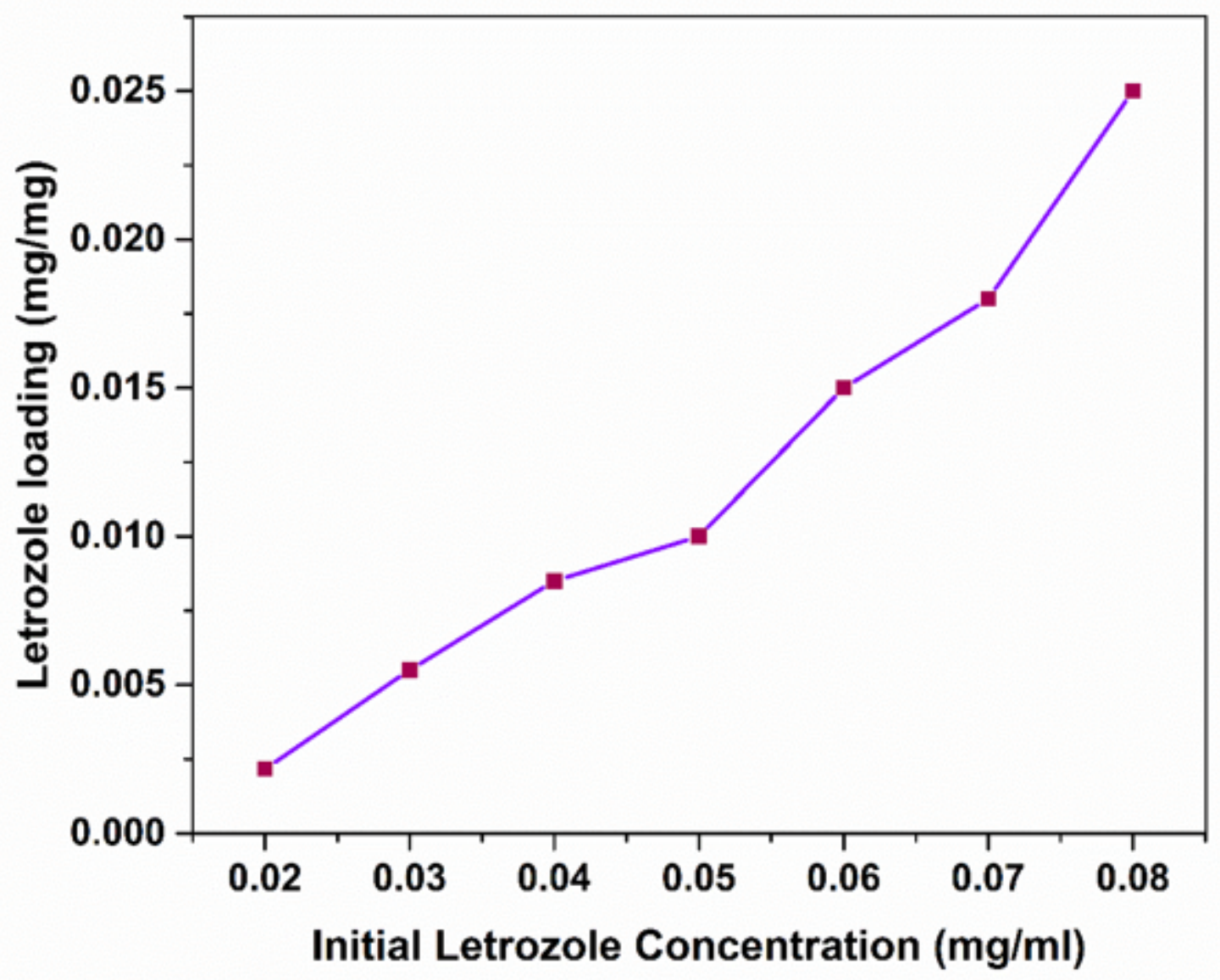

Figure 7

Curve capacity of Letrozole on carrier at different initial Letrozole concentrations. 


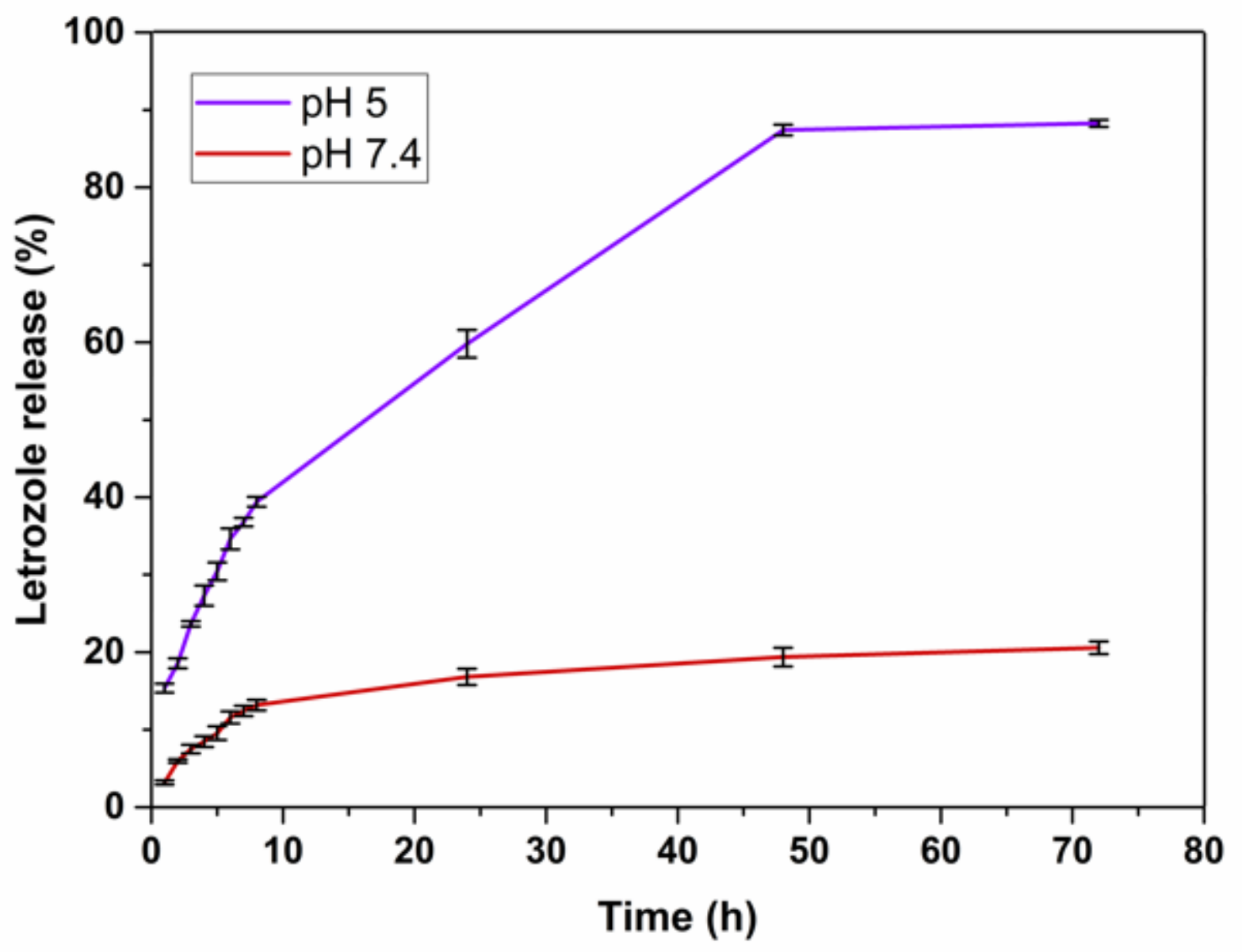

Figure 8

Cumulative release curves of Letrozole from Methionine@CoFe $\mathrm{O}_{4}$ nanoparticlesat pH 5 and 7.4.Data are expressed as mean \pm SD $(n=3)$ 

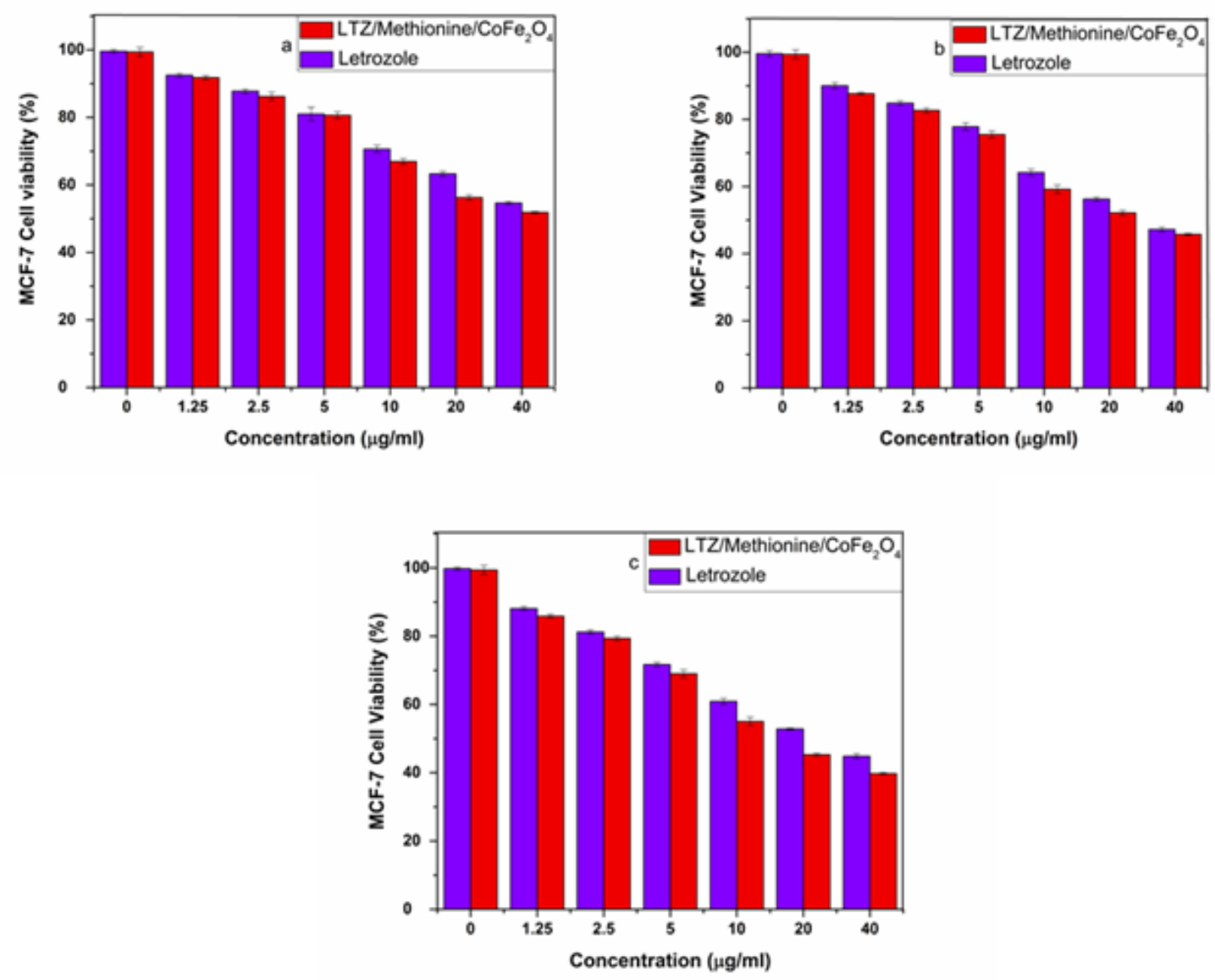

Figure 9

Concentration-dependent survival curves of MCF-7 cells treated by Letrozole-Methionine @ $\mathrm{CoFe}_{2} \mathrm{O}_{4}$ nanoparticles and Letrozole for (a) 24, (b) 48 and (c) 72 h.Data are expressed as mean \pm SD $(n=5)$ 

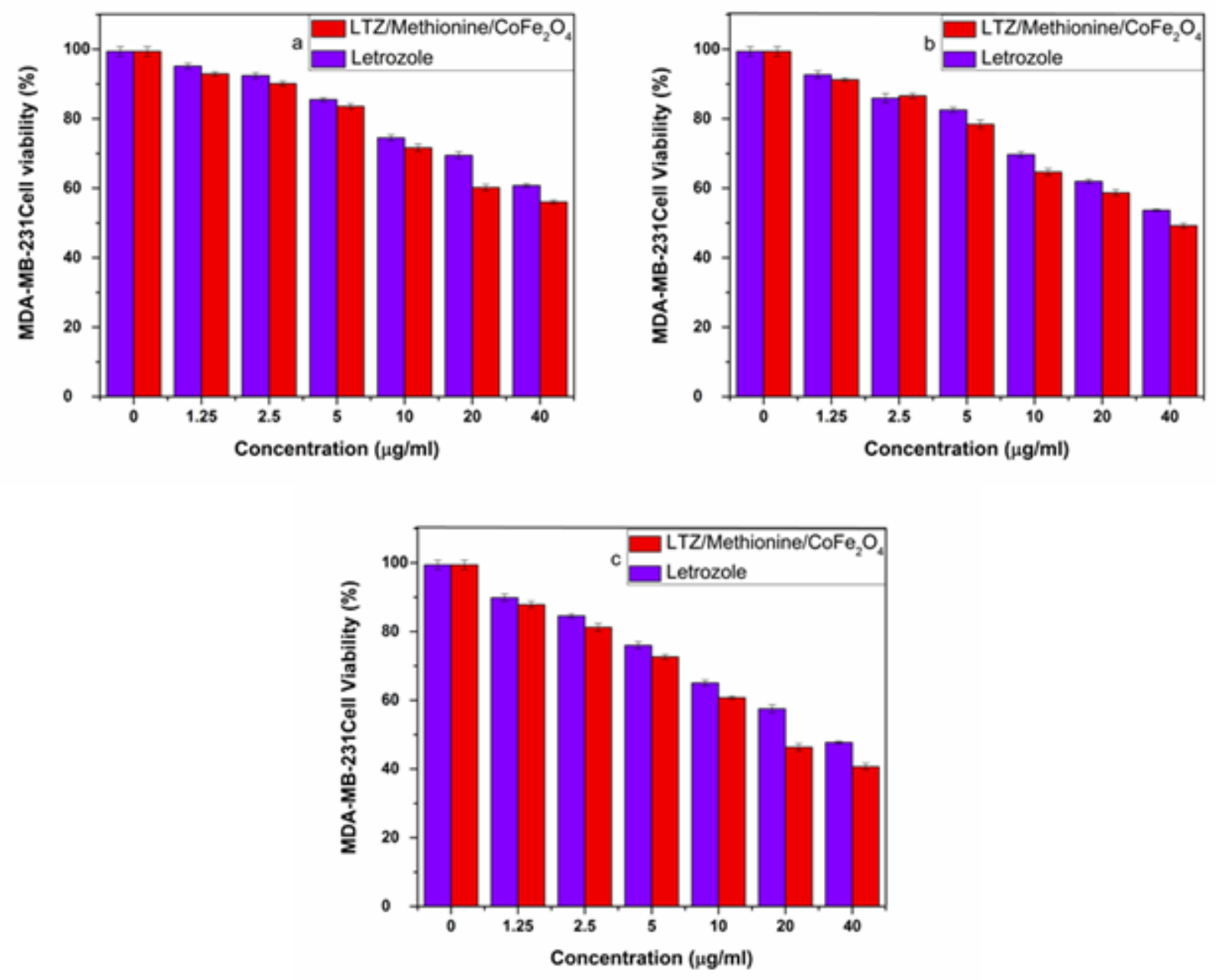

Figure 10

Concentration-dependent survival curves of MDA-MB-231 cells treated by Letrozole-Methionine@ $@ \mathrm{CoFe}_{2} \mathrm{O}_{4}$ nanoparticles and Letrozole for (a) 24, (b) 48 and (c) 72 h.Data are expressed as mean \pm SD $(n=5)$

\section{Supplementary Files}

This is a list of supplementary files associated with this preprint. Click to download.

- GraphicalAbstract.png 